\title{
Mendidik Anak Shaleh: Telaah Atas Kisah Nabi Ibrahim A.S. dan Ismail A.S.
}

\author{
Miftahur Rahmah \\ SD Negeri 12 Sungai Sapih Padang, Indonesia \\ E-mail: miftahurrahmahmpd@gmail.com
}

DOI: $\underline{\text { https://doi.org/10.15548/turast.v7i1.763 }}$

(Diterima: 11 Februari 2019. Disetujui: 24 Juni 2019. Diterbitkan: 30 Juni 2019)

\begin{abstract}
Abstrct
This article examines the efforts of Prophet Ibrahim a.s. educates his son, Ismail, a.s. becames a pious child, by examining his story in the Koran through the library research approach, among the primary sources used are Tafsir Ibn Kathir, Tafsir al-Maraghi, and Tafsir al-Misbah. The results of the study shows that there are seven components of Islamic education applied by the prophet Ibrahim to his son, Ismail is to make the child become taweed and realize pious children; applying the nature of shiddiq, waffa, halim, munib, muhsin, ummah, qanitanlillah, hanif and khalil; cultivate the character of halim, patience, obedience and merciful, using the material aqidah, worship and morals; use the example method, the direct practice method, compassion, dialogue, and prayer; use education periods namely pre-natal and post-natal education.
\end{abstract}

Keywords: Better education, Ibrahim dan Ismail

\section{PENDAHULUAN}

Setidaknya ada tiga hal yang melatarbelakangi penulisan artikel ini. Pertama, selama ini konsep dan teori pendidikan yang diterapkan cenderung pada kajian yang berkiblat ke Barat yang bercorak sekuler. Sementara umat Islam memiliki sumber atau dasar utama dalam pengembangan pendidikan Islam, yaitu Al-Quran dan Sunnah.Namun tidak semua isi AlQuran menjelaskan secara teknis tentang model pendidikan yang ideal.Butuh kajian penafsiran terhadap ayat-ayat Al-Quran sehingga ditemukan konsep pendidikan Islam yang relevan untuk diterapkan dalam konteks kekinian.

Kedua, di antara isi Al-Quran yang mengandung pesan-pesan pendidikan adalah kisah para Nabi dan Rasul. Salah satunya adalah kisah Nabi Ibrahim a.s. yang berhasil mendidik putranya menjadi anak yang shaleh, yaitu Ismail a.s. Meskipun beberapa penelitian telah melakukan kajian terhadap nilai-nilai pendidikan Nabi Ibrahim a.s. namun belum ditemukan 
kajian yang lebih komprehensif dan mendalam tentang upaya Ibrahim a.s. selaku seorang Ayah dalam mendidik putranya sehingga menjadi anak shaleh.

Ketiga, tema pendidikan anak shaleh perlu dikembangkan mengingat istilah tersebut popular dalam dunia Islam, tetapi rumusan untuk mewujudkannya sulit ditemukan dalam literatur pendidikan Islam. Karena adanya Nabi Ibrahim a.s. yang berdoa dianugerahi anak yang shaleh, lalu Ismail a.s pun dijelaskan Al-Quran sebagai hamba yang shaleh-seperti penjelasan di atas-maka penelitian tafsir tarbawi dengan tema pendidikan anak shaleh, patut dilakukan berdasarkan kisah kehidupan Ibrahim a.s. dengan Ismail a.s

Dengan demikian menarik melakukan kajian terhadap kisah Nabi Ibrahim a.s. dan Ismail a.s. dalam kontek pendidikan, khususnya mendidik anak shaleh. Dalam AlQuran dijelaskan bahwa selain Nabi Muhammad SAW, Nabi Ibrahim a.s juga disebut sebagai uswatun hasanah atau contoh teladan yang baik (QS. AlMumtahanah/60: 4). Salah satu keteladanan nabi Ibrahim a.s itu adalah keberhasilannya menjadikan Ismail sebagai anak yang shaleh. Banyak ayat al-Quran yang menjelaskan tentang usaha-usaha yang dilakukan nabi Ibrahim a.s dalam mendidik anaknya menjadi anak yang shaleh.

Anak shaleh merupakan cita-cita setiap orang tua yang beriman kepada Allah SWT.(Shihab, 2007) menjelaskan kata shaleh diambil dari kata shaluha yang dalam kamus-kamus bahasa Al-
Quran sering dijelaskan sebagai antonim dari kata fasid (rusak). Maka kata shaleh diartikan sebagai "tiadanya (terhentinya) kerusakan”, juga bermakna "bermanfaat dan sesuai". Jadi, anak shaleh merupakan anak yang taat, selalu berbuat baik serta memberi manfaat dan tidak membuat kerusakan bagi diri, keluarga dan masyarakat sekitarnya.

Anak shaleh merupakan potret ideal dalam Islam. Namun anak shaleh bukanlah warisan dari orang tua tanpa proses dan pembinaan. Untuk melahirkan anak shaleh, butuh upaya sungguh-sungguh dari orang tua berupa pendidikan, baik terkait dengan tujuan, materi, metode atau strategi yang dilakukan oleh orang tua sebagai penanggungjawab utama bagi anakanaknya. Dan Nabi Ibrahim a.s. yang telah berhasil melahirkan anak shaleh, seperti Ismail a.s, patut dikaji untuk diterapkan oleh umat Muhammad SAW yang membaca Al-Quran.

Sehubungan dengan uraian di atas, artikel ini bertujuan untuk mendeskripsikan keteladanan nabi Ibrahim a.s dalam mendidik nabi Ismail a.s menjadi anak shaleh dengan menelaah kisahnya yang terdapat dalam Al-Quran.

\section{METODE PENELITIAN}

Penelitian ini menggunakan metode libraryresearch, yang menekankan pada medote tafsir maudlu'i. Prosedur penelitiannya adalah dengan mengacu pada kitabkitab tafsir, dengan menggunakan beberapa ahli yang memiliki relevansi 
dengan masalah yang dibahas, di mana penyajiannya bersifat deskriptif dengan menggunakan metode berfikir induktif dan deduktif.

Tafsir yang dijadikan data primer dalam penelitian ini adalah tafsir Ibn Katsir, karya Al-Imam Abul Fida Isma'il Ibnu Kasir Ad-Dimasyqi, M. Quraish Shihab, Tafsir al-Mishbah, dan Tafsir Ahmad Mushthafa al-Maraghi. Sumber sekunder adalah sumber yang sifatnya membantu sumber primer yang ada, yang merupakan data penunjang yang dijadikan alat bantu dalam menganalisis permasalahan yang ada, seperti Kitab-kitab Tafsir, Sistem Pendidikan Islam, teori-teori pendidikan berdasarkan Al-Quran, ilmu pendidikan dalam perspektif Islam, prinsip-prinsip dan metode Pendidikan Islam, Kisah Para Nabi, serta buku-buku dan tulisan-tulisan yang dianggap memiliki hubungan dengan masalah yang dikaji.

Langkah-langkah tafsir Maudhu'i dalam penelitian ini adalah memilih atau menetapkan masalah Al-Quran yang akan dikaji, melacak dan menghimpun ayat-ayat yang berkaitan dengan masalah, menyusun ayat-ayat tersebut secara runtut menurut kronologi masa turunnya dan asbab alnuzul. Mengetahui korelasi (munasabah) ayat, menyusun tema bahasan, dan mempelajari ayat-ayat tersebut secara tematik dan menyeluruh

\section{TEMUAN PENELELITIAN DAN PEMBAHASAN}

\section{Tujuan Pendidikan dalam Kisah Nabi Ibrahim a.s.}

Jika ditelusuri beberapa ayat AlQuran yang mengisahkan Nabi Ibrahim a.s. dengan Ismail, setidaknya ada dua tujuan pendidikan, yaitu: pertama, menjadikan anak bertauhid. Nabi Ibrahim a.s. dikenal sebagai "Bapak Monotheis" karena ia dikenal dengan perjuangannya menegakkan tauhid, meskipun ia harus berhadapan dengan ancaman Raja Namrud yang membakarnya hidup-hidup. Ali (Adhan, 2018; Syariati, 2002) menyebut Nabi Ibrahim sebagai tokoh besar pemberantas kemusyrikan di dalam sejarah. Dia menegakkan tauhid di dunia dengan menanamkan iman ke dalam hati orang-orang kafir sehingga tauhid dapat tumbuh di tengah-tengah kemusyrikan. Ibrahim a.s. pemberantas kemusyrikan, meninggalkan rumah "Azar", pembuat berhala, untuk menghancurkan berhala-berhala dan untuk menghancurkan Namrud.

Setelah terbebas dari kezaliman Namrud, ia tetap berdakwah menegakkan tauhid kepada kaumnya, termasuk kepada keluarganya. Selain perjuangan dakwah dan tarbiyah, ia juga bermohon kepada Allah SWT. agar anak cucunya terhindar dari kemusyrikan, seperti menyembah berhala (Qs. Ibrahim/14:35). (AlMaraghi, 1993) menjelaskan maksud jauhkanlah aku dan keturunanku dari menyembah berhala tetapkanlah kami pada tauhid dan Islam yang telah kami pegang ini dan jauhkanlah kami dari menyembah berhala-berhala agar kami 
memperoleh keridhaan-Mu. Hal ini bagian penting dalam tujuan pendidikan Islam, yaitu mengakui aqidah tauhid sebagai konsep tertinggi manusia dalam mengenal Allah SWT.(Musthafa \& Ammar, 2009).

Kedua, mewujudkan anak shaleh. Nabi Ibrahim a.s. diuji Allah SWT dengan berbagai cobaan, di antaranya lama memiliki keturunan. Namun ia tetap bermunajat kepada Allah agar dianugerahkan anak yang shaleh (Qs. Ash-Shaaffat/37: 100), untuk meneruskan perjuangan dakwahnya di muka bumi ini. (Hamka, 1982, 2015; Ikhwan, 2016; Syafi'i, 2014) menjelaskan permohonan ini dilakukannya setelah dia memutuskan hubungan dengan kaumnya yang durkaha kepada Allah SWT. yang tidak mau lagi diberi pentunjuk. Nabi Ibrahim a.s. melakukan hijrah hati dan hijrah tempat tinggal serta menyerahkan dirinya sepenuhnya kepada Allah SWT. Dalam keadaan penyerahan diri kepada Allah SWT. Itu ia merasakan ada sesuatu hal yang masih kurang, yaitu anak. Maka Nabi Ibrahim a.s memohon kepada Allah SWT. untuk dianugerahi anak yang shaleh.

\section{Karakter Pendidik Shaleh}

Terdapat beberapa ayat Al-Quran yang mengisahkan tentang sifat-sifat Nabi Ibrahim a.s. Sifat-sifat baik yang dimiliki oleh Nabi Ibrahim a.s. tentu melekat dalam dirinya sebagai guru terhadap anak-anaknya, termasuk ketika mendidik Ismail, sehingga sifat itu dapat disebut sebagai karakter pendidik shaleh.
Pertama, shiddiq. Karakter jujur dan benar yang dimiliki oleh Nabi Ibrahim.a.s. itu membuat dirinya menjadi manusia utama pilihan Allah yang diberi gelar sebagai shiddiq atau orang yang benar (Qs. Maryam/19: 41). Sifat shiddiq ini terlihat saat berinteraksi dengan anaknya, Ismail. Ketika Allah SWT. memerintahkan Ibrahim untuk menyembelih putranya melalui mimpi, Nabi Ibrahim menceritakan mimpi itu apa adanya. Dia tidak membohongi anaknya, dan kejujuran itu dibalas oleh putranya dengan ucapan yang meneguhkan ayahnya agar melakukan perintah itu dengan harapan sang ayah memiliki sifat sabar (Qs. ashShaffat/37: 102).

Karakter shiddiq harus dimiliki dan dipelihara oleh seorang pendidik. (Arsyad, 2015; Ruslan, 2016; Siahaan, Hidayat, Wijaya, \& Rifa'i, 2017; Syalhud, 2006), menulis: "Sesungguhnya jujur bagi seorang guru adalah mahkota yang menghiasi kepalanya. Jika ia kehilangan sifat jujur, maka ia kehilangan kepercayaan manusia terhadap ilmunya dan terhadap pengetahuan-pengetahuan yang ia sampaikan kepada mereka."

Sifat jujur merupakan bagian integral dari kompetensi kepribadian yang harus dimiliki oleh seorang pendidik. Dalam Peraturan Menteri Pendidikan dan Kebudayaan Nomor 16 Tahun 2007 tentang Standar Kualifikasi Akademik dan Kompetensi Guru, menegaskan bahwa salah satu butir kompetensi inti dari kompetensi kepribadian yang harus dimiliki oleh guru adalah "Menampilkan diri sebagai pribadi yang jujur, berakhlak 
mulia, dan teladan bagi peserta didik dan masyarakat". Selain kepribadian, seorang pendidik harus jujur pula secara keilmuan, bersifat benar dalam memperlakukan peserta didiknya, dan semua sifat itu akan mendatangkan berbagai kebaikan.

Kedua, waffa, mempunyai arti menyempurnakan janji atau menepati janji (Surasman, 2016). Nabi Ibrahim a.s. senantiasa menepati janji dengan Allah SWT. dalam penyampaian perintah Allah dan risalah-Nya kepada semua makhluk (Qs. An-Najm/ 53: 37). Diantara sifat waffa yang dilakukan Nabi Ibrahim a.s. adalah ketika beliau diperintahkan oleh Allah SWT. untuk melakukan menyembelih putranya Ismail, berhijrah, menyerahkan hartanya berinfak dalam ketaatan, dan dilemparkan ke api sebagai konsekuensi menyampaikan nilai-nilai kebenaran tauhid (mengesakan) Allah SWT (Surasman, 2016).

Menjadi seorang pendidik adalah pilihan. Ketika seseorang memilih profesinya sebagai pendidik, maka ia harus berjanji pada diri sendiri bahwa ia akan melaksanakan tugas-tugasnya sebagai guru dalam mendidik dan mencerdaskan peserta didiknya. Janji itu harus ditepati sehingga apa yang menjadi tujuan pembelajaran dan tujuan pendidikan dapat tercapai dengan baik.

Ketiga, halim. Al-Quran menjelaskan Nabi Ibrahim a.s. sebagai orang yang memiliki karakter halim. Ketika menafsirkan surat Hud/11 ayat 75, (Al-Maraghi, 1993) mengartikan kata halim, yaitu "yang tidak menyukai disegerakannya hukuman". Sedangkan saat menafsirkan surat at-Taubah/9 ayat 114, mengartikan halim, sebagai orang-orang yang tidak bisa dipengaruhi marahnya, sehingga mengancam orang lain. Orang yang memiliki sifat seperti itu, pasti akan menjadi orang yang sabar, pemaaf, berhati-hati dalam segala hal dan tidak tergesa-gesa ketika suka atau ketika duka.

Sifat ini sangat terkait dengan sifat pendidik. Seorang pendidik pasti akan berinteraksi dengan individuindividu yang memiliki karakter yang beragam dengan pola pikir yang berbeda-beda. Di samping itu, pendidik juga dituntut untuk melakukan aktivitas pembaharuan, perbaikan, dan pengajaran yang terus menerus setiap harinya. Aktivitas tersebut diiringi dengan berbagai problematika yang ditimbulkan oleh peserta didik. (Amiruddin, 2018; Febrimardiansyah, 2019; Kawakib, 2016; Muttaqin, 2017; Robika, 2018; Yuliyanti, 2017), ketika menjelaskan etika guru kepada murid, satu diantaranya adalah "Kadang-kadang, dalam kegiatan pembelajaran sering kali ditemukan siswa (terutama siswa pemula) yang tidak serius serta memiliki niat yang kurang tulus. Terhadap hal seperti ini, guru hendaknya bersabar dan tidak menyurutkan semangatnya dalam memberikan pengajaran kepada mereka".

Keempat, awwah (Qs. Hud/11: 75). Menurut (Shihab, 2007), awwah adalah hati yang lembut dan hatinya cepat merasakan kepedihan ketika melihat atau mendengar orang lain ditimpa 
kepedihan. Ini merupakan salah satu sifat terpuji Nabi Ibrahim a.s. yaitu perhatian beliau yang sangat besar terhadap penderitaan orang lain. Kata awwah ini juga dapat diartikan banyak berdoa. Sedangkan (Hamka, 2015) mengartikan sebagai pengiba, iba kasihan melihat orang yang sengsara atau dengan kata lain apabila orang mengeluh tidak sampai melihat orang mendapatkan kesusahan.

Karakter awwah akan membuat seseorang berhati lembut. Sifat lembut adalah bersikap ramah terhadap orang lain baik dalam perkataan maupun perbuatan, tidak mempersulit, dan ia juga berarti kebalikan dari sikap keras dan kasar. Karena itu, sifat ini mesti dimiliki oleh seorang pendidik. Para pendidik hendaknya berusaha bersikap lembut dan menerapkannya terhadap peserta didik mereka (Syalhud, 2006). Selain itu, sebagai seorang guru, seseorang harus memberikan kesempatan yang seluas-luasnya kepada peserta didik dalam menuntut ilmu. Janganlah seorang guru menganggap seorang peserta didik itu bodoh dan tidak dapat lagi diberi kecerdasan. Manusia yang lahir ke dunia ini adalah sesuai dengan fitrahnya, yaitu manusia yang mampu untuk berkembang dan belajar. Hal ini akan mudah dilakukan oleh seorang guru jika ia memiliki kelembutan hati.

Kelima, munib (Qs. Hud/11: 75). Nabi Ibrahim a.s. memiliki karakter munib, yaitu orang yang senantiasa bertaubat atau kembali kepada Allah SWT. Hal ini dirangkaikan dengan sifat sebelumnya, yaitu awwah. (Anwar, Siregar, \& Mustofa, 2015; Wartini, 2014) menjelaskan munīb dapat diartikan dengan kembali ke posisi semula setelah ditinggalkan. Ini mengandung makna introspeksi dan menyesali perbuatan lalu memperbaiki. Menurut Hamka arti kata munīb adalah suka kembali. Orang yang memiliki sikap munīb dalam dirinya maka ia selalu mengembalikan segala urusannya kepada Allah SWT, ia sadar bahwa sejauh-jauhnya berjalan dalam kehidupan ini, namun semua langkah akan kembali kepada Allah SWT.

Guru yang ideal memiliki kesucian hati dan dekat pada Allah SWT. Tugas guru bukan saja mengajarkan ilmu (transfer of knowladge), tetapi lebih dari itu seorang guru bertugas menyucikan jiwa peserta didiknya. Dalam konteks ini, guru disebut muzakki, atau orang yang menyucikan. (Shihab, 2007) menegaskan bahwa kata muzakki termasuk ke dalam pengertian mendidik, sebab mendidik terkait dengan upaya membersihkan diri seseorang dari segala sifat dan akhlak yang tercela. Namun di sisi lain, seorang guru adalah manusia biasa yang bisa saja berbuat salah. Maka guru yang berperan sebagai muzzakki akan senantiasa segera kembali kepada Allah atau bertaubat jika ia terlanjur melakukan kesalahan. Di sinilah pentingnya sifat munīb bagi setiap guru.

Keenam, muhsin (Qs. Ash-Shaffat/ 37: 109-110). Al-Quran juga menjelaskan bahwa Nabi Ibrahim a.s. memiliki sifat ihsan, atau disebut muhsin (orang yang berbuat baik). Dalam tafsir al-Azhar (Hidayat, 2015) 
dijelaskan arti dari muhsin adalah penyerahan diri yang diikuti dengan perbuatan kebajikan dengan sadar. Sedangkan dalam tafsir al-Misbah (2002: 598) disebutkan, muhsin adalah mukmin yang selalu mawas diri dan merasakan kehadiran Allah SWT. Ihsan bagi manusia, bisa tercapai saat manusia memandang dirinya pada diri orang lain, sehingga ia memberi pada orang lain apa yang seharusnya dia berikan kepada dirinya. Sedangkan ihsan antara manusia dan Tuhannya adalah leburnya diri, sehingga dia hanya melihat Allah SWT. Karena itu ihsan antara sesama manusia adalah dia tidak lagi melihat dirinya dan hanya melihat orang lain. Orang yang melihat dirinya pada posisi kebutuhan orang lain dan tidak melihat dirinya pada saat beribadah kepada Allah disebut muhsin. Oleh karena itu makna ihsan menurut sebagian ulama dua yaitu pertama memberi nikmat kepada orang lain dan kedua, perbuatan baik. Maka oleh sebab itu kata ihsan ini lebih tinggi bila dibandingkan dengan kata adil.

Seorang guru harus menjadi muhsin. Ia harus merasakan bahwa ia senantiasa berada dalam pengawasan Allah SWT. sehingga ia memiliki sifatsifat mulia, jauh dari maksiat, dan taat menjalankan perintah-Nya. Hal ini relevan dengan pendapat al-Kinani, seperti dikutip Ramayulis (2012: 118), salah satu syarat guru yang berhubungan dirinya adalah "Hendaknya guru senantiasa insyaf akan pengawasan Allah terhadapnya dalam segala perkataan dan perbuatan bahwa ia memegang amanat ilmiah yang dberikan Allah kepadanya". Karenanya, ia tidak mengkhianati itu, malah ia tunduk dan merendahkan diri kepada Allah SWT". Selain itu, dengan makna sifat ihsan di atas, maka guru akan memberikan pendidikan yang terbaik kepada peserta didiknya. Ia akan berupaya agar peserta didiknya lebih baik dan lebih berhasil dari dirinya sendiri. Tegasnya, dengan sifat ihsan ini, seorang guru akan melandasi aktivitasnya atas dasar iman pada Allah SWT. lalu melakukan upaya terbaik dalam mendidik peserta didiknya.

Ketujuh, ummah (Qs. An-Nahl/16: 120). Ibnu Katsir (2004: 118) mengartian ummah sebagai "imam yang diikuti". (Shihab \& Al Mishbah, 2002) berpendapat kata ummah terambil dari kata amma-ya'ummu yang berarti menuju, menumpu dan meneladani. Dari akar kata yang sama lahir kata umm yang berarti ibu dan imam yang artinya pemimpin. Karena ibu menjadi teladan, tumpuan dan harapan bagi anak-anaknya. Sedangkan pemimpin menjadi teladan, tumpuan pandangan dan harapan bagi bawahannya.

Jika dikaitkan dengan kajian pendidik, maka ummah erat kaitannya dengan kompetensi kepribadian. Dalam Undang-undang Nomor 14 Tahun 2005 tentang Guru dan Dosen, pada penjelasan pasal 10, yang dimaksud dengan kompetensi kepribadian adalah kemampuan kepribadian yang mantap, berakhlak mulia, arif, dan berwibawa serta menjadi teladan peserta didik. Seorang guru dituntut memiliki ragam sifat mulia yang berkumpul dalam dirinya sehingga ia menjadi teladan dan figur 
sentral bagi peserta didik dan masyarakat sekitarnya.

Kedelapan, qānitan lillah (Qs. AnNahl/16: 120). Qānit atau qānut berarti orang yang khusyu' lagi patuh (Katsir, 2005), atau orang yang patuh kepada Allah dan melaksanakan perintah-Nya (Al-Maraghi, 1993), walaupun harus menyembelih putranya sendiri (Hamka, 2015). Guru sebagai pendidik, harus memiliki sifat qānit. Pendidik yang qānit konsisten mengamalkan perintah Allah, baik yang fardhu maupun yang sunnah. Ketaatan kepada Allah yang dilakukan secara terus-menerus itu memberi keteladan pada peserta didiknya secara mudah. Para peserta didik termotivasi dari pendidik yang mereka saksikan sendiri ketaatan dan kemuliaan akhlaknya.

Kesembilan, al-hanif, artinya"orang yang menyimpang dari agama yang batil menuju agama yang haq" (AlMaraghi, 1993), "orang yang berpaling dari kemusyrikan menuju kepada tauhid. Bahkan dalam ayat ini, Nabi Ibrahim a.s. ditegaskan sebagai imam bagi orang-orang hanif, dalam kata ummatan qānitan lillahi hanífa.Ajaran Nabi Ibrahim adalah hanif maksudnya adalah ajaran yang dibawa oleh Nabi Ibrahim adalah ajaran yang tidak bengkok, tidak memihak kepada pandangan hidup orang-orang Yahudi dan tidak juga mengarah kepda ajaran Nasrani atau ajaran apapun yang bertentangan dengan ajaran Ilahi Yang Maha Esa itu (Shihab \& Al Mishbah, 2002).

Setiap pendidik yang beragama Islam mesti memiliki tauhid yang benar. Dengan dasar tauhid yang benar, maka setiap guru dituntut bersifat ikhlas dan mengharap ridha Allah dari setiap usaha yang ia lakukan dalam mendidik peserta didiknya. Ia tidak boleh bermaksiat, apalagi dihadapan peserta didiknya. Ia harus menjadi cahaya yang menerangi peserta didiknya menuju kebenaran hakiki, tunduk dan patuh kepada Allah SWT. (Al-Abrasyi, 2003) menegaskan salah satu sifat guru adalah bersih, tidak saja bersih tubuhnya, tetapi juga jauh dari dosa dan kesalahan, bersih jiwanya, terhindar dari dosa besar, sifat ria, perselisihan dan sifat-sifat tercela lainnya.Hal itu akan dapat terwujud dan terjaga jika ia tetap pada fitrahnya yang hanif.

Kesepuluh,khalil, artinya "teman yang meresap di dalam kalbunya, persahabatan dan kecintaan" (Shihab \& Al Mishbah, 2002). Kata ini pada mulanya berarti celah, karena itu kata ini juga dapat diartikan sebagai teman yang selalu mengetahui dan mengenal, baik secara umum maupun secara khusus sampai kepada celah-celah atau rahasia temannya. Siapa saja yang memiliki sifat ini pastilah selalu mendampingi temannya itu. Nabi Ibrahim a.s diberi gelar Khalil karena relung-relung kalbunya telah dipenuhi oleh cinta kepada Allah SWT. dan karena ia meneladani sifat-sifat-Nya maka Allah SWT. pun mencintai beliau.

Pendidik yang ideal dalam Islam juga harus mencintai Allah SWT.di atas segala-galanya. Ia mendidik bukan karena alasan materi atau kenikmatan duniawi yang sesaat. (Al-Abrasyi, 2003) menempatkan hal ini menjadi 
sifat pertama yang harus dimiliki oleh pendidik, yaitu "zuhud, tidak mengutamakan materi, dan mengajar karena mencari keridhaan Allah semata". Seorang pendidik harus berupaya menjadi hamba yang dicintai Allah SWT. karena ketaatan dan kemuliaan akhlaknya lalu berupaya mendidik peserta didiknya menjadi hamba yang dikasihi-Nya.

Dari sepuluh sifat Nabi Ibrahim a.s. yang diperoleh dari Al-Quran di atas menunjukkan bahwa sifat-sifat tersebut relevan dengan sifat pendidik saat ini. Jika dikaitkan dengan sistem pendidikan di Indonesia, sifat-sifat ini termasuk dalam kategori kompetensi kepribadian, di antara tiga kompetensi lainnya: kompetensi sosial, pedagogik dan profesional. Kompetensi kepribadian inilah yang paling berperan dalam menampilkan seorang guru teladan. Kompetensi kepribadian pula yang paling berperan dalam mendidik karakter peserta didik.

\section{Karakter Anak Shaleh}

Sifat Ismail dapat dianalisis sebagai karakter anak shaleh, khususnya ketika ia berinteraksi dengan ayahnya, Nabi Ibrahim a.s. Karakter anak shaleh yang dimiliki oleh Ismail itu dapat dijadikan sebagai teladan bagi peserta didik. Di antara sifat Ismail a.s. yang paling menonjol adalah halim, taat, sabar dan penyayang.

\footnotetext{
Halim mengandung karakter santun, sabar dan bijaksana. Kesantunan Ismail terhadap ayahnya juga terlihat dari sikap dan ucapan
}

sang anak saat Nabi Ibrahim a.s. menyampaikan kepadanya perintah Allah agar dia disembelih berdasarkan suatu mimpi (Shihab \& Al Mishbah, 2002). Sifat santun atau amat sabar dituntut dimiliki oleh peserta didik. Dengan kesantunan itu, ia disayangi oleh gurunya sehingga setiap materi yang diajarkan mudah diserap oleh peserta didik. (Asy'ari, 2007) menegaskan sifat santun menjadi bagian penting dalam etika peserta didik kepada gurunya. Hormat dan santun tidak saja terwujud dalam bentuk kepatuhan pada guru, tetapi juga tampak dalam bersikap saat duduk di depan guru serta berbicara dengan baik dan sopan di hadapan guru.

Ketika Ismail tumbuh menjadi anak yang mulai berakal dan menginjak remaja, Allah menguji Nabi Ibrahim a.s. dengan perintah mengurbankan Ismail dengan cara menyembelihnya. Perintah Allah itu dikomunikasikan Nabi Ibrahim a.s. kepada Ismail lalu Ismail menerimanya dengan taat dan sabar (Qs. AshShaaffat/37:102). Salah satu sifat peserta didik adalah sabar dan menjauhkan diri dari perlakuan yang kurang baik dari gurunya dan jangan menutup diri dan terus berupaya menyertainya dengan menduga ada nilai-nlai positifnya, dan hendaklah ia tetap menduga terhadap perbuatan guruyang secara lahiriah tampak buruk, tetapi pada hakikatnya tetap baik (Ghoni, 2017; Nata, 2001). Sebagaimana nabi Ismail a.s tetap sabar dan bersedia untuk disembelih oleh ayahnya, walaupun ia akan kehilangan nyawanya sendiri. Ismail a.s. yakin apa 
yang dilakukan oleh ayahnya itu adalah atas perintah Allah SWT. bukan kerana kebencian sang ayah kepada dirinya.

Ismail juga memiliki karakter penyayang. Karakter penyayangnya tampak dari bahasa yang ia gunakan, seperti digambarkan dalam Qs. AshShaaffat/37:102, Ismail a.s memanggil ayahnya dengan panggilan yang mulia dan penuh kasih sayang, yaitu "wahai bapakku" ketika menjawab panggilan bapaknya "Ya Bunayya" (Al-Maraghi, 1993).

Pendidik adalah pengganti orang tua bagi anak ketika berada di lingkungan sekolah. Peserta didik seyogyanya memanggil guru dengan panggilan yang baik sebagai bentuk kasih sayang dan penghormatannya kepada seorang guru. Wujud penghormatan seorang pelajar kepada seorang guru diantaranya adalah tidak memanggil gurunya dengan panggilan "kamu", "anda" dan lain sebagainya. Hendaklah seorang peserta didik memanggil gurunya dengan menggunakan sebutan: "Ya Sayyidi (wahai tuanku), "Ya Ustadzi" (wahai guruku) dan lain sebagainya. Disamping itu seorang peserta didik juga tidak sepantasnya menyebut nama gurunya dihadapan orang lain kecuali dengan menyebutkan kata-kata yang mulia sebagai wujud penghormatannya terhadap guru tersebut (Asy'ari, 2007).

\section{Materi Mendidik Anak Shaleh}

Materi pendidikan yang terdapat dalam kisah Nabi Ibrahim a.s dan
Ismail a.s. dikelompokkan ke dalam tiga bagian, yaitu akidah, ibadah dan akhlak. Pertama, bidang akidah, di antaranya tidak memperserikatkan Allah SWT (Qs. Al-Hajj/ 22: 26), beriman kepada Allah dan hari akhir (Qs. al-Baqarah/2: 126) dan Al-Asma' al-husna (al-Baqarah/2: 127-129).

Dalam tafsir Al-Azhar (Hidayat, 2015) dijelaskan bahwa Qs.alHajj/22:26 menjelaskan perintah kepada Nabi Ibrahim a.s. untuk mendirikan rumah tempat ibadah kepada Allah SWT. dan menegakkan akidah keesaan Allah SWT. di rumah yang didirikannya itu. Jangan sampai tempat itu dijadikan sebagi tempat membuat pujaan yang lain. Dalam tafsir al-Maraghi (Al-Maraghi, 1993) dijelaskan bahwa Nabi Ibrahim a.s. yang telah membangun dan menjadikannya sebagai rumah bagi manusia. Dia diperintah untuk membersihkannya dari kemusyrikan bagi kepentingan orang-orang yang melakukan tawaf dan shalat, dan menyeru manusian untuk datang ke tempat itu dari seluruh penjuru dunia (untuk melaksanakan ibadah haji).

Dalam pendidikan Islam, materi akidah yang terkait dengan tauhid dan tidak menyekutukan Allah adalah materi yang paling dasar. Materi aqidah merupakan salah satu ruang lingkup Pendidikan Agama Islam di antara empat ruang lingkup lainnya (Al-Quran Hadis, Akhlak, Ibadah dan Tarikh). Materi ini diajarkan sejak usia dini sehingga keimanannya kokoh. Untuk kelas III tingkat Sekolah Dasar, misalnya, peserta didik telah diajarkan materi tentang "Keesaan Allah" 
(Permendiknas, n.d.). Biasanya, guru akan menjelaskan tentang larangan menyekutukan-Nya.

Sedangkan Qs. al-Baqarah/2: 126 dijelaskan bahhwa Nabi Ibrahim a.s. tidak saja berdoa agar negeri Mekah yang ia tempati menjadi aman dan sentosa secara lahiriah, tetapi yang terpenting mendoakan mereka agar beriman kepada Allah dan hari kemudian (man amana minhum billahi wal yaumil akhir). Nabi Ibrahim a.s. memberikan penekanan pada anak dan keturunannya agar beriman kepada Allah SWT. Inilah materi paling pokok dalam pendidikan Islam. Materi iman kepada Allah dan hari akhir ini seharunya ditanamkan oleh setiap guru dalam diri peserta didik. Jika terdapat guru mata pelajaran umum, materi iman kepada Allah sesungguhnya dapat diintegrasikan dalam setiap materi yang relevan. Semua ilmu yang diajarkan idealnya mendidik setiap peserta didik untuk semakin dekat dengan Allah SWT. sebagi Tuhan yang memberikan ilmu tersebut. Setiap ilmu yang diperoleh dan dikembangkan peserta didik akan mendatangkan kemaslatahan karena didasari oleh iman yang kuat. Inilah yang disebut dengan tauhid ilmu, atau integrasi ilmu (Hanifah, 2018; Lubis, 2016; Riyadi, 2000).

Dalam Qs. al-Baqarah/2: 127-129 dijelaskan pula ketika Nabi Ibrahim a.s. berdoa agar amalnya diterima, maka ia menyebut al-asma al-husna: al-sami' al'alim, Yang Maha Mendengar lagi Maha Mengetahui. Tentu, setiap doa pasti didengar Allah dan Dia Maha Mengetahui makna setiap doa sebagaimana yang dimaksud oleh hamba-Nya. Ketika Nabi Ibrahim a.s. memohon agar taubat mereka diterima, ia menyebut al-asma' al-husna: al-tawwab al-rahim, Yang Maha Penerima Taubat dan Maha Penyayang. Hanya dengan kasih sayang Allah-lah dosa-dosa hamba-Nya dapat diampuni. Sementara doa Nabi Ibrahim a.s. tentang nasib generasi sesudahnya agar diselamatkan dengan diutusnya seorang Rasul yang mengajarkan alKitab dan al-Hikmah, ia pun menyebut al-asma al-husna: al-'Aziz al-Hakim, Allah Yang Mahakuasa dan Maha Bijaksana. Hanya kekuasaan Allah dan kebijaksanaan-Nya yang dapat menyelamatkan generasi sesudahnya. Mengenal nama-nama Allah SWT.yang terangkum dalam al-asma' al-husna sangat penting untuk mengokohkan iman kepada-Nya. (Al Jauziyah, 2000) menegaskan bahwa ilmu tentang Allah, baik berkenaan dengan namanama, sifat-sifat, dan perbuatanperbuatan-Nya adalah sebaik-baik ilmu. Sedangkan posisi ilmu ini jika dibandingkan dengan ilmu-ilmu yang lain adalah bagaikan kedudukan Allah di antara semua makhluk-Nya. Dan ilmu ini paling mulia karena ia merupakan sumber segala ilmu.

Kedua, materi ibadah, diantaranya haji dan shalat (Qs. Al-Hajj/22: 26). Pokok ajaran Islam yang sudah diajarkan semenjak zaman Nabi Ibrahim adalah Ibadah haji dan shalat. Allah SWT. memerintahkan kepada Nabi Ibrahim melaksanakan thawaf di Baitullah serta rukuk dan sujud (shalat) sebagai wujud ibadah mahdhah kepadaNya. Haji dan shalat sangat penting diajarkan kepada peserta didik karena 
materi pokok Pendidikan Islam. Apalagi shalat, merupakan ibadah utama yang menentukan dan mempengaruhi kualitas ibadah lainnya.

Ketiga, dalam bidang akhlak, ada beberapa materi yang terdapat dalam kisah nabi Ibrahim a.s. dan Ismail a.s. yaitu sabar dan patuh terhadap perintah orang tua karena Allah SWT. (Qs. Ash-Shaaffat/37: 102), patuh kepada suami karena Allah SWT. dan menepati janji (Qs. Maryam/ 19: 54). Ketenangan hati yang ditunjukkan oleh Ismail a.s. ketika ayahnya memberitahukan bahwa Allah SWT. memerintahkan supaya ayahnya segera menyembelihnya, menujukkan sikap sabar yang dimiliki oleh Ismail. Jawaban yang diberikan oleh Ismail juga merupakan jawaban yang luar biasa, yaitu: "Hai bapakku! Kerjakanlah apa yang diperintahkan kepadamu! Insya Allah kamu akan mendapatkanku termasuk orang-orang yang sabar.

Sementara itu,ucapan Ismail: if'al matu'marun/laksanakanlah apa yang diperintahkan kepadamu, bukan berkata sembelihlah aku, mengisyaratkan sebab kepatuhannya adalah karena hal itu adalah perintah Allah SWT. Bagaimanapun bentuk, cara, dan kandungan apa yang diperintahkan-Nya, ia sepenuhnya pasrah (Shihab \& Al Mishbah, 2002). Patuh kepada orang tua merupakan suatu yang mesti dilakukan oleh seorang anak. Sikap patuh yang ditunjukkan anak kepada kedua orang tuanya merupakan salah satu amal yang paling disukai Allah SWT.
Dalam buku "Kisah Bapak dan Anak dalam al-Quran" digambarkan tentang kepatuhan Hajar terhadap suaminya Ibrahim a.s karena melaksanakan perintah Allah SWT. walaupun akibatnya Hajar harus hidup dalam kekurangan dan kesusahan tetapi dia yakin bahwa Allah SWT. tidak akan menyia-nyiakannya (Halim \& Musthafa, 2007). Kepatuhan seorang isteri terhadap suami merupakan akhlak terpenting dalam berumah tangga. Suami adalah pemimpin dalam keluarga. Tanpa kepatuhan seorang isteri, maka kepemimpinan ayah akan terganggu. Ketidakpatuhan isteri pada suami berdampak pada pendidikan anak-anak mereka. Padahal pendidikan di rumah tangga merupakan fondasi utama untuk menanamkan akhlak mulia.

Materi akhlak lainnya adalah menepati janji. Sebelumnya, telah dijelaskan bahwa Nabi Ibrahim juga memiliki sifat menepati janji (Qs. Maryam/ 19: 54). Sementara (AlMaraghi, 1993) mengungkapkan, tidak pernah Ismail menjajikan suatu janji pun, kecuali dia pasti menepatinya sehingga dia berjanji kepada ayahnya akan bersabar ketika disembelih. Ternyata dia buktikan janjinya itu, dia menepati apa yang dikatakannya, dan mentaati perintah sehingga datang tebusan baginya.

Ketiga materi ini tidak membatasi materi pendidikan lainnya yang dibutuhkan dalam mendidik karakter anak shaleh. Akan tetapi materi akidah, ibadah, dan akhlak merupakan materi pokok dalam ajaran Islam. Ini pula yang menjadi pelajaran diterima Rasulullah SAW. dari Jibril yang 
menyerupai manusia saat mengajarkan tentang Iman, Islam, dan Ihsan. Pengembangan materi tetap perlu dilakukan dengan menjadikan materi iman (akidah) sebagai poros utama yang diikuti Islam (ibadah) dan ihsan (akhlak).

\section{Metode Mendidik Anak Shaleh}

Metode pendidikan anak dalam kisah nabi Ibrahim a.s. dan Ismail a.s. diantaranya adalah metode keteladanan, metode praktek langsung, metode kasih sayang, metode dialog, dan metode doa. Pertama, keteladanan Nabi Ibrahim a.s. terlihat saat ia mengajak anaknya meninggikan dasardasar Baitullah, Ka'bah. Saat itu, Ibrahim a.s. tidak saja menyuruh Ismail bekerja, tetapi juga terjun langsung bekerja. Ismail menyodorkan batu-batu yang diperlukan, dan Ibrahim a.s. yang menyusun dan memasang batu itu (Kosim, 2008). Inilah sebuah keteladanan dari kekasih Allah (khalilullah) yang turut berbuat untuk agama Allah (Qs. al-Baqarah/2: 127).

Dalam proses pendidikan, metode keteladanan menekankan pada pendidik bahwa mendidik peserta didik tidak hanya transfer ilmu, tetapi perlu internalisasi nilai melalui keteladanan (Tafsir, 2017). Keteladanan dari seorang guru tidak saja kepada peserta didik, tetapi kepada semua orang yang memandangnya sebagai guru (Mulyasa, 2008). Apalagi antara pendidik dengan peserta didik senantiasa terjadi interaksi sehingga peserta didik akan terpengaruh dengan perilaku pendidiknya (Abdullah, 1991), sebab manusia lebih banyak belajar dari apa yang mereka lihat (Bambang, 1987; Mahmudah, 2017) menyebut bahwa sangatlah mudah bagi pendidik mengajari peserta didik dengan berbagai materi pendidikan secara lisan, akan tetapi sesuatu yang teramat sulit bagi peserta didik untuk melaksanakannya ketika ia melihat orang mendidiknya tidak memberi contoh atau mengamalkannya. (Arifin, 2015) juga menyebut bahwa metode keteladanan terhadap peserta didik, terutama anak-anak yang belum mampu berpikir kritis, akan banyak mempengaruhi pola tingkah laku mereka dalam kehidupan sehari-hari. Guru sebagai pembawa dan pengamal nilai-nilai agama, kultural dan ilmu pengetahuan akan memperoleh manfaat dalam mendidik anak apabila menerapkan metode ini, terutama dalam pendidikan akhlak dan agama serta sikap mental peserta didik. Jika guru menerapkan metode keteladanan, maka konsekuensinya ia harus dapat memberikan teladan kepada para peserta didiknya dengan berusaha mencontoh dan meneladani Rasulullah SAW. sebagai teladan sejati, baik dari segi sikap perbuatan, termasuk ibadahnya (Syahidin, 2009).

Kedua, metode praktik langsung. Nabi Ibrahim a.s. mendidik anaknya tidak sekedar mendoakan akan kesalahen anaknya, tetapi juga mendidik Ismail a.s. dengan melibatkannya secara langsung melakukan hal-hal yang baik, seperti adalah saat membangun Ka'bah (Qs. al-Baqarah/2: 127). Dalam tafsir Ibn Katsir, diceritakan bahwa pembangunan Ka'bah ini saat Ismail telah dewasa dan memiliki isteri. 
Namun (Shihab \& Al Mishbah, 2002) menyebut peristiwa ini terjadi saat Ismail masih remaja. Nabi Ibrahim a.s. berkata: "Wahai Ismail, sesungguhnya Allah memerintahkan sesuatu kepadaku". "Laksanakanlah apa yang diperintahkan Rabb-mu itu," sahut Ismail. Ibrahim pun bertanya: "Apakah engkau akan membantuku?" "Aku pasti akan membantumu," jawab Ismail. Ibrahim bertutur: "Sesungguhnya Allah menyuruhku untuk membangun sebuah rumah di sini." Seraya menunjuk ke anak bukit kecil yang lebih tinggi dari sekelilingnya. Pada saat ini keduanya meninggikan pondasi Baitullah. Ismail mengangkat batu, Ibrahim memasangnya. Hingga ketika bangunan itu sudah tinggi, dia datangkan sebuah batu, dan dia meletakkannya untuk dijadikan pijakan. Ibrahimpun berdiri di atasnya sambil memasang batu, sementara Ismail menyodorkan batu kepadanya. Keduanya pun berdoa: rabbana taqabbal minna innaka anta as-sami'u al-'alim.

Jadi, Nabi Ibrahim a.s. sebagai orang tua mengajak anaknya Ismail untuk membangun Ka'bah. Ia melibatkan Ismail untuk membangun rumah Allah. Tentu, hal ini memberikan pengalaman spiritual secara langsung kepada Ismail untuk menjalankan perintah Allah SWT. Seperti yang disebut (Shihab \& Al Mishbah, 2002), mereka meninggikan pondasi bangunan Ka'bah. Mereka berdua tidak menerima upah dari siapapun. Mereka hanya memohon agar amalnya diterima Allah sebagai pengabdian: Terimalah dari amal kami, yakni meninggikan dasar-dasar
Ka'bah, sesungguhnya Engkau Maha Mendengar permohonan kami dan Maha Mengetahui kerja, niat, dan tujuan kami. Inilah pengalaman spiritual yang akan mempengaruhi keimanan dan perilaku sang anak. Kepatuhan pada perintah Allah, keikhlasan dalam berbuat, dan menghasilkan karya berupa rumah Allah, merupakan bagian dari proses pendidikan yang meninggalkan bekas pada pribadi anak sehingga ia akan menjelma menjadi seorang hamba yang taat kepada Allah SWT.

Ketiga, metode kasih sayang (Qs. Ash-Shaaffad/ 37: 102). Kata Ya Bunayya yang berarti "Wahai ayahku", merupakan ungkapan kasih sayang dari seorang ayah kepada anaknya. Metode kasih sayang yang didahului oleh bahasa Nabi Ibrahim a.s. ya Bunayya, dibalas pula oleh putranya dengan kata ya Abati, sebagai ungkapan kepatuhan dan ketundukan pada perkataan dan perintah ayahnya atas dasar cinta karena Allah SWT (AlMaraghi, 1993).

Metode kasih sayang dapat mewujudkan hubungan yang baik antar individu (Thuwairaqi, 2004). Dalam proses pembelajaran, kasih sayang seorang guru kepada peserta didik sangat dibutuhkan, karena ia merupakan kebutuhan jiwa setiap orang (Al-Qusy, 1974; Mawangir, 2015). Bahkan kasih sayang (rahmah) adalah sifat wajib dimiliki oleh setiap pendidik. Orang yang hatinya keras tidak layak menjadi pendidik (Abdurrahman \& al-Maroky, 2005). Dalam tradisi pesantren sebagai lembaga pendidikan Islam di Indonesia, misalnya, kasih sayang 
seorang guru kepada santri diyakini mendatangkan barakah dari ilmu yang diajarkan. Keberkahan ilmu itu akan diperoleh jika "Guru sayang kepada murid dan murid hormat kepada guru." Sebab sentuhan kasih sayang yang ditampilkan dalam komunikasi harmonis antara pendidik dengan terdidik, sehingga guru dirasakan selalu hadir dalam seluruh konteks kehidupan muridnya (Syahidin, 2009). Jadi, metode kasih sayang efektif dilakukan untuk mendidik karakter seorang anak. Dengan kasih sayang, diharapkan perkembangan mental anak akan optimal tanpa rasa takut dan terancam.

Keempat, metode dialog. Nabi Ibrahim a.s. berdialog kepada anaknya, Ismail a.s. dengan bahasa yang dilandasi kasih sayang: "Hai anakku sesungguhnya aku melihat dalam mimpi bahwa aku menyembelihmu. Maka pikirkanlah apa pendapatmu!". Pertanyaan itu juga dijawab oleh sang putra dengan santun: "Hai bapakku, kerjakanlah apa yang diperintahkan kepadamu; insya Allah kamu akan mendapatiku termasuk orang-orang yang sabar" (Qs. asy-Syaffat/37: 102).

Dialog Nabi Ibrahim a.s. dengan Ismail juga termasuk dialog naratif. Dialog naratif tampil dalam episode kisah yang bentuk dan alur ceritanya jelas sehingga menjadi bagian dari cara atau unsur cerita dalam Al-Quran. Walaupun Al-Quran mengandung kisah yang disajikan dalam bentuk dialog, kita tidak dapat mengidentikkan keberadaannya dengan drama yang sekarang ini muncul sebagai sebuah jenis karya sastra. Artinya, Al-Quran tidak menyajikan unsur dramatik walaupun dalam penyajian kisahnya terdapat unsur dialog (Syahidin, 2009).

Kelima, metode doa. Doa orang tua memiliki peran penting dalam melahirkan anak yang saleh. Jumuah Saad menegaskan untuk melahirkan anak yang kelak menjadi tokoh teladan, salah satu metodenya adalah "tak pernah lelah dalam berdoa untuk mereka". Doa telah ditegaskan dalam sebuah hadits Nabi sebagai senjata bagi orang-orang yang beriman, $a d-d u^{\prime} a$ shilaahul mu'minin. Oleh karena itu, relevan jika doa dijadikan sebagai metode utama mendidik anak. Para Nabi dan orang-orang saleh terdahulu banyak melakukan metode doa ini, seperti Nabi Ibrahim a.s. (ashShaffaat/37: 100 dan al-Furqaan/25: 74), keluarga Imran (Ali Imran: 38), Nabi Zakariya a.s. (al-Anbiyaa': 89 dan Maryam: 5), Nabi Nuh a.s. (Nuh: 28), dan lain-lainnya.

Dalam kisah Nabi Ibrahim a.s. terdapat beberapa doa yang ia mohonkan kepada Allah SWT.untuk kebaikan anak-anaknya. Di antara doa itu adalah agar diberi keturunan yamg saleh (Qs. Ash-Shaaffat/37: 100), berdoa agar keturunan dijadikan sebagai imam (Qs. Al-Baqarah/2 : 124), berdoa kepada Allah SWT. agar lingkungan yang dipilihnya sebagai tempat tinggal isteri dan anaknya menjadi lingkungan yang baik (Qs alBaqarah/2: 126), berdoa kepada Allah SWT. agar lingkungan yang baik tetap menjadi baik bagi perkembangan anaknya (Qs. Ibrahim/14: 37), dan berdoa kepada Allah SWT. agar anaknya Ismail dan keturunannya 
yang lain menjadi hamba yang selalu berserah diri kepada Allah SWT. (Qs. Al-Baqarah/2: 128).

Doa orang tua untuk anaknya bukan saja sebelum kelahirannya, tetapi juga selama proses pendidikan berlangsung. Orang tua harus berupaya untuk mendidik anakanaknya agar menjadi saleh, namun usaha itu harus diiringi dengan doa, sebab mendidik anak tidak bisa dilepaskan dari hidayah Allah SWT. Di sinilah pentingnya metode doa, seperti yang dilakukan oleh Nabi Ibrahim a.s. terhadap anak-anaknya, termasuk Ismail a.s.

\section{Periodesasi Mendidik Anak Shaleh}

Secara umum, periodesasi pendidikan anak dalam kisah Nabi Ibrahim a.s. dan Ismail bisa dibagi ke dalam dua bagian, yaitu pendidikan pra-natal (qabla wiladah) dan pascanatal ( $b a^{\prime} d a$ wiladah). Pada masa Pranatal Nabi Ibrahim as mengutamakan isteri yang shalehah dan berdoa kepada Allah agar dikaruniakan anak yang shaleh.

Sejarah mengungkapkan bahwa isteri pertama Nabi Ibrahim a.s. adalah Siti Sarah. Setelah beberapa lama menikah dan tidak kunjung memperoleh keturunan, maka atas saran Sarah, Ibrahim menikah dengan budak atau pembantu mereka yang berkulit hitam, bernama Siti Hajar. Ibrahim bersedia menikahi Siti Hajar, perempuan yang amat sederhana, berstatus budak (Katsir, 2008), berkulit hitam; bukan berparas cantik dan bukan pula kaya raya. Akan tetapi
Hajar adalah seorang hamba yang beriman, taat, berhati mulia dan berakhlak terpuji. Dengan begitu, Ibrahim termasuk gambaran orang yang mengedepankan isteri karena keimanan dan kemuliaan akhlaknya, meskipun hanya seorang budak.

Setelah menikah dengan Siti Hajar nabi Ibrahim a.s. berdoa kepada Allah SWT. agar dikaruniai anak yang shaleh. Dalam tafsir Ibnu Katsir dijelaskan bahwa ketika Nabi Ibrahim sudah berusaha untuk mengajak kaumnya menyembah Allah, tetapi mereka tetap membangkang, maka Nabi Ibrahim menyerahkan semuanya kepada Allah SWT. dan dia segera meninggalkan mereka. Namun Nabi Ibrahim a.s. tidak pernah berputus asa beliau memohon kepada Allah SWT. agar diberi keturunan yang shaleh yang akan melanjutkan perjuangannya menegakkan agama Allah SWT. seperti ditulis dalam Qs. Ash-Shaaffat/37: 100 di atas..

Doa Nabi Ibrahim a.s. ini mengajarkan kepada kita bahwa untuk mendidik anak, tidak bisa dilakukan semata-mata dengan usaha belaka, atau dengan membanggakan diri kita sebagai orang yang terdidik, tetapi butuh kepasrahan jiwa memohon pertolongan-Nya. Apalagi mendidik aqidah atau sikap keberagamaan anak, dibutuhkan hidayah dari Allah SWT. Maka bermohonlah kepada-Nya dengan tetap berupaya memenuhi kewajiban-kewajiban kita sebagai seorang hamba.

Pada masa pasca-natal Nabi Ibrahim a.s. dalam mendidik anakanaknya senantiasa memanjatkan doa 
yang terbaik untuk pertumbuhan dan perkembangan anaknya, diantaranya mendoakan keturunan kita menjadi imam (Qs. Al-Baqarah/2: 124), mendoakan anak agar menjadi orang yang berserah diri kepada Allah (Qs. Al-Baqarah/2: 128), hijrah dari lingkungan yang tidak baik kepada lingkungan yang baik demi kelangsungan pendidikan anak dan mendoakan lingkungan yang sudah dipilih itu agar terhindar dari keburukan serta berlimpah anugerah kesejahteraan (Qs. Ibrahim/ 14: 37), mendoakan lingkungan yang baik menjadi tetap baik untuk pertumbuhan dan perkembangan anak (Qs. Ibrahim/14: 35) dan berwasiat tentang agama kepada anak sebelum ajal menjemput (Qs. Al-Baqarah/2: 132).

Demikian beberapa tahapan yang dilakukan oleh Nabi Ibrahim a.s. dalam mendidik Ismail setelah kelahiran hingga ia dewasa. Nabi Ibrahim a.s. menjadi seorang ayah teladan yang peduli akan keimanan dan kesalehan anak cucunya. Karena itu, beberapa Nabi juga dilahirkan dari silsilah Nabi Ibrahim, termasuk Nabi Muhammad SAW. silsilahnya sampai kepada Nabi Ismail dan Nabi Ibrahim a.s.

\section{KESIMPULAN}

Tujuan pendidikan nabi Ibrahim a.s. adalah menjadikan anak bertauhid dan mewujudkan anak yang shaleh. Sifat nabi Ibrahim sebagai seorang pendidik, yaitu shiddiq, waffa, halim, munib, muhsin, ummah, qanitanlillah, hanif dan Khalil, lebih menekankan pada kompetensi kepribadian yang menjadi modal penting terwujudnya pendidik teladan dan berkarakter. Sifat nabi Ismail sebagai peserta didik, yaitu halim, sabar, taat dan penyayang, menjadi karakter anak shaleh yang perlu ditumbuhkembangkan melalaui pendidikan. Materi pendidikan nabi Ibrahim a.s. adalah dalam bidang aqidah, ibadah dan akhlak yang menjadi materi inti dalam pendidikan Islam. Metode yang digunakan adalah keteladanan, metode praktek langsung, metode kasih sayang, metode dialog, dan metode doa. Periodesasi pendidikan bisa dibagi ke dalam dua bagian, yaitu pendidikan pra-natal (qabla wiladah) dan pasca-natal ( $b a^{\prime} d a$ wiladah). Pada masa Pranatal Nabi Ibrahim a.s. mengutamakan isteri yang shalehah dan berdoa kepada Allah agar dikaruniakan anak yang shaleh. Pada masa pasca-natal Nabi Ibrahim a.s. dalam mendidik anak-anaknya senantiasa memanjatkan doa yang terbaik untuk pertumbuhan dan perkembangan anaknya, memilih lingkungan yang baik, serta berwasiat tentang agama kepada anak sebelum ajal menjemput.

Upaya Nabi Ibrahim a.s. dalam mendidik Ismail yang diceritakan dalam Al-Quran tentu tidak detil seperti yang ditemukan dalam kajian pendidikan Islam. Akan tetapi, informasi Al-Quran tersebut menekankan pentingnya upaya itu untuk dilakukan oleh umat manusia, termasuk umat Nabi Muhammad SAW. Sebab upaya-upaya di atas tetap relevan diterapkan di setiap zaman sehingga melahirkan anak-anak yang saleh. 


\section{REFERENSI}

Abdullah, A. R. S. (1991). Educational Theory, A Quranic Outlook (Alih bahasa: Mutammam). Bandung: Diponegoro.

Abdurrahman, H., \& al-Maroky, W. F. (2005). Membangun kepribadian pendidikan umat: Ketauladanan Rasulullah SAW di bidang pendidikan. Wadi Press.

Adhan, S. R. (2018). Theology of Liberation in Thought Of Ali Shari'ati. Journal of Islam and Science, 3(2), 259-288.

Al Jauziyah, I. Q. (2000). Asma-ul Husna. Terjemahan oleh Samson Rahman.

Al-Abrasyi, M. (2003). Prinsip-prinsip Dasar Pendidikan Islam. Bandung: Pustaka Setia.

Al-Maraghi, A. M. (1993). Terjemahan Tafsir Al-Maraghi. Penerjemah: Bahrun Abuba.

Al-Qusy, A. A. (1974). Pokok-pokok Kesehatan Jiwa/Mental.

Terjemahan Zakiah Daradjat. Jakarta: Bulan Bintang.

Amiruddin, M. F. (2018). Konsep Pendidikan Islam Menurut KH. Hasyim Asy'ari. JURNAL DIRASAH, 1(1), 17-31.

Anwar, M., Siregar, L., \& Mustofa, H. (2015). Cahaya, cinta, dan canda: $M$. Quraish Shihab. Lentera Hati.
Arifin, H. M. (2015). The Influence of Competence, Motivation, and Organisational Culture to High School Teacher Job Satisfaction and Performance. International Education Studies, 8(1), 38-45.

Arsyad, J. (2015). Karakteristik Rasulullah Sebagai Pendidik: Perspektif Sirah Nabawiyah. ITQAN: Jurnal Ilmu-Ilmu Kependidikan, 6(2), 75-90.

Asy'ari, H. (2007). Etika Pendidikan Islam. Yokyakarta: Titian Wacana.

Bambang, Q. (1987). Anees dan Adang Hambali. 2008. Pendidikan Karakter Berbasis Al.

Febrimardiansyah, F. (2019). Studi kritis perbandingan konsep Pendidikan Islam KH Hasyim Asy'ari dan KH Ahmad Dahlan (PhD Thesis). UIN Sunan Ampel Surabaya.

Ghoni, A. (2017). Pemikiran Pendidikan Naquib al-Attas Dalam Pendidikan Islam Kontemporer. Jurnal Lentera: Kajian Keagamaan, Keilmuan Dan Teknologi, 3(1), 196-215.

Halim, A. M., \& Musthafa, A. (2007). Kisah Bapak dan Anak dalam alQur'an. Trans.: Al-Katani, AH $\mathcal{E}$ Wardie, F.. Gema Insani Press.

Hamka. (2015). Juz'Amma tafsir alAzhar: Diperkaya dengan pendekatan sejarah, sosiologi, tasawuf, ilmu kalam, sastra, dan psikologi. Gema Insani.

Hamka, B. (1982). Tafsir Al-Azhar Buya Hamka. Ahadi Kurniawan. 
Hanifah, U. (2018). Islamisasi Ilmu Pengetahuan Kontemporer (Konsep Integrasi Keilmuan di Universitas-Universitas Islam Indonesia. TADRIS: Jurnal Pendidikan Islam, 13(2), 273-294.

Hidayat, U. T. (2015). Tafsir Al-azhar: Menyelami Kedalaman Tasawuf Hamka. Buletin Al-Turas, 21(1), 49-76.

Ikhwan, A. (2016). Manajemen Perencanaan Pendidikan Islam (Kajian Tematik Al-Qurâ€ $€^{\mathrm{TM}}$ an dan Hadist). EDUKASI: Jurnal Pendidikan Islam, 4(1), 128-155.

Katsir, I. (2005). Tafsir Ibnu Katsir jilid 1, terj. M. Abdul Ghoffar, Dkk (Bogor: Pustaka Imam Asy Syafi'I, Cet-4.

Katsir, I. (2008). Qishashul Anbiya (Kisah Para Nabi). Surabaya: Amelia.

Kawakib, A. (2016). Tujuan Pendidikan Islam. Al-Fitrah, 10(1).

Kosim, M. (2008). Mendidik Kesalehan Ritual dan Sosial. Jakarta: Rineka Cipta.

Lubis, H. (2016). Pengembangan Metode Integratif dalam Pembelajaran Sains. Jurnal Tarbiyah, 23(1).

Mahmudah, U. (2017). Konsep pendidikan anak persepektif'Abd Nashih'ulwan (PhD Thesis). UIN Raden Intan Lampung.

Mawangir, M. (2015). Zakiah Daradjat dan Pemikirannya tentang Peran Pendidikan Islam dalam Kesehatan Mental. Intizar, 21(1), 83-94.
Mulyasa, E. (2008). Menjadi Guru Profesional Menciptakan Pembelajaran.

Musthafa, S. F., \& Ammar, W. M. (2009). Kurikulum pendidikan anak Muslim. Pustaka Elba.

Muttaqin, A. (2017). Pemikiran pembaharuan Pendidikan Islam: Studi komparasi atas pemikiran $\mathrm{KH}$. Hasyim Asy'ari dan KH. Ahmad Dahlan, implementasinya dalam Pendidikan Islam di Era Global (PhD Thesis). Universitas Islam Negeri Maulana Malik Ibrahim.

Nata, A. (2001). Perspektif Islam tentang pola hubungan guru-murid: Studi pemikiran tasawuf Al-Ghazali. Rajagrafindo Persada (Rajawali Pers).

Permendiknas, R. I. (n.d.). No. 16 Tahun 2007 tentang. Standar Kualifikasi Akademik Dan Kompetensi Guru.

Riyadi, H. (2000). Tauhid Ilmu dan Implementasinya Dalam Pendidikan. Nuansa, Bandung.

Robika, S. (2018). Pandangan KH Hasyim Asy'ari tentang konsep hakikat dan tujuan pendidikan Islam ( $\mathrm{PhD}$ Thesis). UIN Sunan Ampel SurabayA.

Ruslan, R. (2016). Etika Guru dalam Proses Belajar Mengajar. AlRiwayah: Jurnal Kependidikan, 8(1), 59-72.

Shihab, M. Q. (2007). "Membumikan" Al-Quran: Fungsi dan peran wahyu dalam kehidupan masyarakat. Mizan Pustaka. 
Shihab, M. Q., \& Al Mishbah, T. (2002). Pesan, Kesan dan Keserasian AlQur'an. Jakarta: Lentera.

Siahaan, A., Hidayat, R., Wijaya, C., \& Rifa'i, M. (2017). Konsep-konsep keguruan dalam pendidikan islam. Lembaga Peduli Pengembangan Pendidikan Indonesia.

Surasman, O. (2016). Melek Al-Qur'an; Bercerminkan Karakter Nabi Ibrahim As. Ulul Albab Jurnal Studi Islam, 17(1), 47-70.

Syafi'i, A. M. (2014). Pengaruh Tafsir al-Manar terhadap Tafsir alAzhar. MIQOT: Jurnal Ilmu-Ilmu Keislaman, 38(2).

Syahidin, D. H. (2009). Menelusuri Metode Pendidikan dalam AlQuran. Bandung: CV. Alfabet.

Syalhud, F. bin A. A. (2006). Guruku Muhammad SAW. Gema Insani.
Syariati, A. (2002). Makna haji. Jakarta: Pustaka Ahra.

Tafsir, A. (2017). Filsafat Pendidikan Islam.

Thuwairaqi, A.-N. (2004). Sekolah Unggulan Berbasis Sirah Nabawiyah. Pentrj, Asmuni, Jakarta: Darul Falah.

Wartini, A. (2014). Corak Penafsiran M. Quraish Shihab dalam Tafsir alMisbah. Hunafa: Jurnal Studia Islamika, 11(1), 109-126.

Yuliyanti, R. (2017). Hubungan Guru Dan Murid Menurut Kh. Hasyim Asy'ari Dan Implementasinya Dalam Tradisi Pembelajaran Di Pondok Pesantren Nurul Hikmah (PhD Thesis). UIN Raden Intan Lampung. 